\title{
Violent and Threatening Behavior of War Veterans with Post Traumatic Stress Disorder! The Forced Psychiatric Treatment is an Obligation, or is A Violence of Human Rights? Case Presentation
}

\author{
Halimi R* \\ Department of Psychiatry, Gjilan Regional Hospital, Kosovo
}

*Corresponding author: Ramadan Halimi Department of Psychiatry, Gjilan Regional Hospital, Kosovo, E-mail: ramadan_halimi@yahoo.com

Citation: Halimi R (2018) Violent and Threatening Behavior of War Veterans with Post Traumatic Stress Disorder! The Forced Psychiatric Treatment is an Obligation, or is A Violence of Human Rights? Case Presentation. SAJ Case Rep 5: 306

Article history: Received: 28 June 2018, Accepted: 27 August 2018, Published: 28 August 2018

\begin{abstract}
This article presents the definition and nature of Posttraumatic Stress Disorder, Psychotic Depression as its co-morbidity, and consequences of untreated cases and also presents the models of treatment and psychological mechanisms of coping. In case report is presented a male patient 38 y/o and detailed history of his diseases. Based on International Classification of Diseases 10-th version (ICD-10), Post-traumatic stress disorder (PTSD) arises as a delayed or protracted response to a stressful event or situation of an exceptionally threatening or catastrophic nature, which is likely to cause pervasive distress in almost anyone. Military personnel are among the most atrisk populations for exposure to traumatic events and the development of PTSD. As in our presented case, untreated victims may develop additional serious medical and psychological complications in the aftermath of traumatic events. Those complications may evolve from PTSD, be co-morbid with PTSD, or exist by themselves. In our presented case, untreated PTSD has resulted with disability, medical and legal expense, disorganization in family and social environment and intense psychological distress. The toll in human suffering is enormous and unacceptable
\end{abstract}

Keywords: PTSD; Co-Morbidity; Psychotic Depression; Treatment; Coping;

\section{Introduction}

Based on International Classification of Diseases 10-th version (ICD-10), Post-traumatic stress disorder (PTSD) arises as a delayed or protracted response to a stressful event or situation of an exceptionally threatening or catastrophic nature, which is likely to cause pervasive distress in almost anyone. Typical features include episodes of repeated reliving of the trauma in intrusive memories ("flashbacks"), dreams or nightmares, occurring against the persisting background of a sense of "numbness" and emotional blunting, detachment from other people, unresponsiveness to surroundings, anhedonia, and avoidance of activities and situations reminiscent to the trauma. There is usually a state of autonomic hyper-arousal with hyper vigilance, an enhanced startle reaction, and insomnia.

The onset follows the trauma with a latency period that may range from a few weeks to months. The course is fluctuating but recovery can be expected in majority of cases. In a small proportion of cases the condition may follow a chronic course over many years [1].

Several trauma theorists suggest that cognitive factors have critical impact on the trauma response, particularly in the persistence of PTSD through negative beliefs and appraisals of ongoing threat [2]. For example, central in cognitive models of PTSD is the assumption that perception of stressful event as a threat may be at least as important as trauma severity and variation in pre-trauma experience in the development and maintenance of PTSD [3].

Military personnel are among the most at-risk populations for exposure to traumatic events and the development of PTSD. Unfortunately, the past century has tragically produced an ongoing supply of combat-traumatized soldier to study. emphasized that" The overwhelming evidence proves beyond a doubt that war is a disease that kills, maims, not just by tearing apart soldiers' bodies, but also by ravaging their minds [4]. 
Co-morbidity is common and is an important factor in understanding clinical impairment in PTSD. Sub-threshold PTSD also contributed independently to level of impairment. Of war importance sub-threshold PTSD is associated with a significantly higher wish for suicidal ideation, Obsessive Compulsive Disorder, Panic disorder, or Social phobia and Depressive disorder [5]. Individuals closest to a person with major psychiatric disorder may suffer most, and the effects of such problems can extend from one generation to the next. PTSD, one possible sequel to exposure to on unusual and intensively disturbing event, often exerts such a strange and pervasive negative influence on those around sufferer. Veterans with PTSD are much likely report martial, parental, and family adjustment problems. There is more violence in the families of veterans with PTSD [6]. Risk factors that enhance the probability of being traumatized include genetics, limited intelligence, limited formal education, and limited social support [7]. Veterans with more PTSD symptoms are probably also more depressed and angry [8].

In addition to PTSD, untreated victims may develop additional and serious medical and psychological complications in the aftermath of traumatic events. Those complications may evolve from PTSD, be co-morbid with PTSD, or exist by themselves. They include, GAD, panic, major depression, dysthymia, somatoform disorder and personality disorder. Untreated trauma and PTSD may result in permanent disability, medical and legal expense, social and community disorganization and intense psychological distress. The toll in human suffering is enormous and unacceptable [7]. Psychotic depression as psychological deterioration of PTSD, is characterized by presence of auditory hallucinations occurring in the absence of any other features; presence of delusions with periods of overlapping mood episodes, inappropriate affects, fatigue, irritability, difficulty on concentrating, feelings of hopelessness or helplessness, feelings of worthlessness or self-hate, social isolation, loss of interest in activities once found pleasurable [1].

According to Council of Europe Committee of Ministers Recommendation, an involuntary treatment should take place only if all of the following conditions are met: (a) the person has a mental disorder; (b) the person's condition represents a significant risk of serious harm to his or her health or to other persons; (c) no less intrusive means of providing appropriate care are available; (d) the opinion of the person concerned has been taken into consideration [9]. People with mental and psychosocial disabilities in lowincome and middle-income countries continue to experience a wide range of human rights violations, including the inability to access adequate mental health services in a safe, therapeutic, and affordable setting. Rights violations also include being subjected to stigma and discrimination in the community, particularly in relation to employment, and being denied the opportunity to exercise legal capacity and civil, social, and political rights [10]. Involuntary treatment of mentally disabled is regulated by Kosovo Law on Mental Health as well. Involuntary treatment is permitted only if: there is a severe mental disorder that limits his / her ability to understand or control his / her behavior; or the person endangers life, health or safety of himself or the others [11].

\section{Coping with Trauma}

Generally, humans react with distinct coping strategies to different types of stress; Active coping strategies (e.g. confrontation, fight, escape) are usually elicited if the stressor or threat is controllable or escapable; Passive coping strategies (e.g. immobility, disengagement) are evoked if the stressor is uncontrollable or inescapable; Interestingly, recent anatomical studies indicate that different natural circuits mediate active and passive emotional coping strategies [12]. In the context of traumatic stress, active or instrumental coping strategies, such as positive thinking or dealing actively with problems have been associated with a (good) adaptation to stress, while passive coping strategies such as avoidance are most often considered as maladaptive coping strategies [13]. Seeking social support is another active coping strategy in dealing with traumatic stress. More specifically, beneficial effects of disclosing or discussing the event have consistently been reported among individuals who have experienced a wide range of traumatic events [14]. Coping should be seen as a process and an understanding of coping in relation to any one type of stressor must take into account how coping with that stressor may change over time $[15,16]$.

A failure to regulate the biological stress response at the time of trauma may result in a cascade of psychobiological alterations that lead to intrusive recollections of event, avoidance of reminders of the event, and symptoms of hyper arousal $[17,18]$.

\section{Case Report}

Mr. J A, 38 y/o, retired war veteran. First admission in Psychiatric Department, mandatory hospitalized, admission was assisted by Police service. He was brought to Psychiatry due to extreme violent behavior in the family environment, sleeplessness for days, disorganized speech and distrust against every one.

\section{History of the Disease}

During the war of 1999 in Kosovo, he has been witness of violence of opposing forces against the civilian population, and of killings and mass deportations of unarmed civilians. He has been an active participant in the resistance front. In 2008 was diagnosed as post-traumatic stress disorder. Throughout all post-war years had manifested insomnia, nightmares, difficulty to focus on the topics of conversations, boredom, irritability and fear of loss of control, feelings of guilt and a sense that he is being followed and being controlled by foreign security services. The diagnosis was made based on clinical evaluation and psychological testing with Harvard Trauma Questionnaire and beck depression inventory (BDI).

From 2008 he experienced several episodes of worsening of PTSD; each time refused treatment, or had taken only a few days treatment. 
Lately he has been experiencing hearing voices, usually threatening "voices" from his murdered comrades. "They" have criticized him for being chickenhearted and betrayer, sometimes these voices were threatened him with death if he refuses to restart the fights and revenges on the enemy for all those crimes made on our families and other civilians. In addition, he was confident that the enemy had convinced his neighbors to keep records of all his movements; recently he has "noticed" how people whispering about him whenever he walks out in the street. Two weeks prior to hospitalization he behaved very violently, has built new fence, on the fence has fixed small cans with different colored wires "to ensure protective measures" against enemy intruders. In the meanwhile the patient had made exercise schedule for all family members as well a detailed list of tasks for each. He had forced the family to wakes at 5 am every day for morning exercises; arguing that everyone has to be prepared for a new war which will come soon. Also, he had monitored regularly the performance of each family member. Due to non-fulfillment of the tasks given by him, last days he became very violent.

\section{Case Personal History}

He is married and has 4 children. In the period of time 1994-1998 he has had a very successful career as mechanic. In 1998 he volunteered in the Kosova Liberation Army, until June 1999 participated in many battles, 3 times had got serious bodily injuries, and still keeps two pieces of shells on the left leg and stomach. Due to those disabilities he wasn't been able to continue previous profession. After the war is unemployed, lives on social assistance of 44 euro / month. Throughout the postwar period was confined to the house, he had avoid contacts with the war comrades; had avoids all activities that have consistently reminded him the war, almost never participated in the anniversaries of war events. Has consistently emphasized that feels guilty for the loss of family members and the loss of many comrades. He's never been involved in any psycho-social rehabilitation program;

\section{Diagnostic and Laboratory Investigations}

The detailed physical examinations revealed no abnormalities. Biochemical and hematological blood tests were within normal limits. Brain MRI: none pathology. EEG: no abnormal forms of activity.

\section{Mental Status Examination}

Patient was oriented in time place and persons, appropriately dressed with evident fear in facial expression, hyper-vigilant, in all questions he answered whispering, inappropriate affect, extreme depressive mood, prominent auditory hallucinations and persecutory and reference delusions.

Based on clinical findings patient was diagnosed as Psychotic depression in co morbidity with PTSD

\section{Treatment}

After three month of combined therapy of medications (Antipsychotics, Antidepressants, and Anxiolytics) and prolonged exposure therapy, results were very satisfactory; patient has been discharged from hospital in an emotionally stable status, with appropriate content of thoughts and with no perception disturbances.

\section{Conclusion}

Early involvement in psycho-social rehabilitation programs, employment and providing opportunities for social problem solving and monitoring of mental health professional institutions of all war veterans diagnosed with PTSD significantly reduce the possibility of manifestation of co-morbid disorders. After all, professional treatment of the veterans with PTSD and co morbid disorders is an obligation and presents the respect of human rights.

\section{Patient's Perspective}

My life situation is getting better; I feel fully family support and support from society; for the first time after almost 14 years I can meet regularly all my war comrades, and have started to participate in anniversaries of post-war events.

\section{References}

1. American Psychiatric Association (2013) DSM-V.

2. Ehlers A, Steil R (1995) Maintenance Of Intrusive Memories In Posttraumatic Stress Disorder; A Cognitive Approach. Behav. Cogn. Ther 23: 217-49.

3. Ehlers A, Clark D (2000) A Cognitive Model Of Posttraumatic Stress Disorder; Behavior Research And Therapy 38: 319-45.

4. Coleman P (2006) Flashback: Posttraumatic Stress Disorder, Suicide, and the Lessons of War. Boston, Beacon Press.

5. Marshall R, Olfson M, Hellman F, Blanco C, Guardino M, et al. (2001) Co-morbidity, Impairment, and Suicidality in sub-threshold posttraumatic stress disorder. Am J Psychiatry 158: 1467-73.

6. Jordan KB, Marmar Ch, Fairbank J, Schlenger E, Kulka R, et al. (1992) Problems In Families Of Male Vietnam Veterans With Posttraumatic Stress Disorder. J Consult Clin Psychol 60: 916-26.

7. Flannery R. (1999) Psychological Trauma And Posttraumatic Stress Disorder-A Review. Int J Emerg Ment Health 2: 135-40.

8. Koenen K, Stellman JM, Stellman SD, Sommer JF (2003) Risk Factors For Course Of Posttraumatic Stress Disorder Among Vietnam Veterans. J Consult Clin Psychol 71: 980-6.

9. FRA (2012) European Union Agency For Fundamental Rights. Involuntary Placement And Involuntary Treatment Of Persons With Mental Health Problems: P26. 
10. Drew N, Funk M, Tang S, Lamichhane J, Chávez E, et al. (2011) Human Rights Violations Of People With Mental And Psychosocial Disabilities: An Unresolved Global Crisis. Lancet 378: 1664-75.

11. Law 05/L-025 (2015) On Mental Health.

12. Keay KA, Bandler R (2001) Parallel Circuits Mediating Distinct Emotional Coping Reactions To Different Types Of Stress. Neurosci Biobehav Rev 25: 669-78.

13. Silver RC, Holman EA, McIntosh DN, Poulin M, Gil-Rivas V, et al, (2002) Nationwide longitudinal study of psychological response to September 11. JAMA 288: $1235-44$.

14. Bolton EE, Glenn DM, Orsillo S, Roemer L, Litz BT (2003) The Relationship Between Self-Disclosure And Symptoms Of Posttraumatic Stress Disorder In Peacekeepers Deployed To Somalia. J. Trauma Stress 16: 203-10.

15. Lazarus R (2000) Toward Better Research On Stress And Coping. Am Psychol 55: 665-73.

16. Lazarus R, Delongis A, Folkman S, Gruen R (1985) Stress And Adaptational Outcomes. The Problem of Confounded Measures. Am Psychol 40: 770-9.

17. Olff M, Langeland W, Gersons BP (2005) The psychobiology of PTSD: coping with trauma. Psycho-neuroendocrinology 30: 947-82.

18. International Classification Of Diseases Tenth-Version: ICD-10, 234-60. 